\title{
Housing materials as predictors of under- five mortality in Nigeria: evidence from 2013 demographic and health survey
}

\author{
Stephen Ayo Adebowale ${ }^{1}$ Oyewale Mayowa Morakinyo ${ }^{2^{*}}$ and Godson Rowland Ana ${ }^{2}$
}

\begin{abstract}
Background: Nigeria is among countries with high Under-Five Mortality (U5M) rates worldwide. Both maternal and childhood factors have been linked to U5M in the country. However, despite the growing global recognition of the association between housing and quality of life, the role of housing materials as predictors of U5M remain largely unexplored in Nigeria. This study, therefore, investigated the relationship between housing materials and U5M in Nigeria.

Methods: The study utilised the 2013 Nigeria Demographic and Health Survey data. A representative sample of 40,680 households was selected for the survey. The sample included 18,516 women of reproductive age who had given birth in the past 5 years prior the survey; with attention on the survival status of the index child (the most recent delivery). Data were analysed using descriptive statistics, Chi-square, Cox-proportional hazard and Brass 2-parameter models $(a=0.05)$.

Results: The hazard ratio of U5M was $1.46(C . I=1.02-1.47, p<0.001)$ and $1.23(C . I=1.24-1.71, p<0.001)$ higher among children who lived in houses built with inadequate and moderate housing materials respectively than those in good housing materials. Under-five deaths show a downward trend (slope $=-0.4871$ ) relative to the housing materials assessment score. The refined U5M rate was 143.5, 127.0 and 90.8 per 1000 live birth among women who live in houses built with inadequate, moderate and adequate housing materials respectively. Other predictors of U5M were; the size of the child at birth, preceding birth interval, prenatal care provider, residence and education. Under-five death reduces with increasing maternal level of; education, wealth quintile, media exposure and housing material type and mostly experienced by Muslim women (6.0\%), rural women (6.5\%) and women residence in the North-West geopolitical zones (6.9\%).
\end{abstract}

Conclusions: Living in houses built with poor housing materials promoted U5M in Nigeria. Provision of sustainable housing by the government and the maintenance of existing housing stock to healthful conditions will play a significant role in reducing the burden of U5M in Nigeria.

Keywords: Housing materials, Under-five mortality, Nigeria

\footnotetext{
* Correspondence: wahlemirax@gmail.com

${ }^{2}$ Department of Environmental Health Sciences, Faculty of Public Health,

College of Medicine, University of Ibadan, Ibadan, Nigeria

Full list of author information is available at the end of the article
} 


\section{Background}

Housing is a key determinant of health and quality of life [1]. Housing is designed to provide shelter and protection from hazards resulting from the physical and social environments. It promotes physical and mental health and ensures the social and economic well-being and quality of life of individuals and households [2]. A person's home is an essential locus for everyday life [3]. Environmental living conditions, including housing conditions and their association with health have drawn the attention of public health scientists since ancient times [4].

Healthy housing has been defined as dwellings and premises that are built and maintained in ways that support the health of its occupants [5, 6]. In the year 1996, the United Nations Habitat conference that held in Istanbul defined healthy housing to include the provision of adequate physical, chemical, biological and mental conditions that supports health, comfort and privacy [7].

Researchers have established that good housing conditions are indispensable in improving household health. Poor housing and environmental conditions can predispose to adverse health problems, including infectious diseases (respiratory disorders), stress and depression [8]. The wellbeing of household occupants is a reflection of the building materials from which the house is built $[9,10]$. One of the established ways through which housing influences health is by human exposure to poor housing conditions, lack of improved water sources, ineffectual waste disposal methods, invasion by disease vectors and inappropriate food storage techniques [11].

Deficient and worsening housing conditions can trigger a range of diseases, including lung diseases, neurological disorders, mental and behavioural dysfunction, which mostly unduly affect children [12]. Children are predominantly susceptible to housing-related hazards than adults since they spend comparably more time indoors. They are seen as a risk group because they require a higher amount of air inhalation than adults, and their organs are not fully developed [13, 14]. Children also have larger surface area to total body mass, thus causing increased exposure to pollutants [15].

Child mortality is a core indicator for measuring the level of child health and well-being in all nations [16]. It is an important indicator of the performance of the health system of a country [17]. Since the beginning of the twentieth century, childhood mortality has been at the centre of health discourse. Health professionals and policy makers have reserved a unique interest in combating the increasing childhood mortality rates [18]. This interest has not only extended globally, it has led to the development of logical approaches to reducing child mortality by two-thirds among children under the age of 5 years between 1990 and 2015, as tagged in the United Nation's Millennium Development Goals (MDGs) [18].
With 133 of the 195 countries that adopted the MDGs failing in meeting the target of a two-thirds reduction in U5M rate, the United Nations in 2015 adopted the Sustainable Development Goals (SDGs) with the intention of safeguarding healthy lives and ensuring the well-being of all children. The goal 3 target 3.2 of the SDGs is to halt preventable deaths of newborns and under-fives by the year 2030 [19].

Under-five mortality rate is highest in sub-Sharan Africa with 1 child in 12 dying before 6 months, which translates to more than 12 times higher than the 1 in 147 average in developed countries [16]. India and Nigeria account for more than one-third of all underfive deaths globally [20]. Currently, Nigeria has the highest reported number of under-5 deaths in Africa [21] with about one million of them dying annually [22]. A number of factors are contributory to this high prevalence of under-five mortality in Nigeria [20, 23-32].

Provision of healthy housing and the continuous maintenance of existing housing stock in such a way as to support and promote human health remain a huge challenge in many countries $[9,33]$. In sub-Saharan Africa more than $60 \%$ of urban dwellers live in slums [34], characterised with poor housing, insufficient space, unimproved water and sanitation. Though the association between living in healthy housing and good quality of life have been described in many developed nations, the links between housing and under-five mortality remain largely unexplored in developing nations [35].

While many studies and reports (including the 2013 report of the Nigeria Demographic and Health Survey) have indicated that the demographic characteristics of both mothers and children play an important role in a child survival [36], there is dearth of information on the role of housing materials in the causation of under-five child mortality while controlling for mother and child individual level factors. To this end, the present study seeks to advance the existing knowledge beyond the understanding of medical-related or personal characteristics by examining the influence of housing conditions and other environmental factors on under-five mortality in Nigeria.

\section{Methods \\ Study area}

The study was carried out in Nigeria, with a human population figure of above 180 million. Nigeria is characterised with high infant and childhood mortality. The maternal mortality ratio is also one of the highest among developing nations worldwide [36]. High fertility is a key factor for high under-five mortality across countries [37]. In Nigeria, the total fertility rate remains high (TFR $=5.5)$ [36]. Unfortunately, the contraceptive prevalence rate of $10 \%$ is still considered as low [36]. Nigeria 
is seen on the global page as poverty stricken country with a striking gap between the rich and the poor. Administratively, Nigeria is made up of 36 states and the Federal Capital territory. Each state has local government areas (third level of government) which are further divided into localities. The country is also stratified into 6 geopolitical zones; North-Central, North-East, North-West, South-East, South-South and South-West. The reason being that Nigeria comprised approximately 400 ethnic groups and 450 dialects. There was the need for the government to unify similar groups into zones for effective allocation of resources. The inhabitants in each of the geopolitical zones are homogeneous and share similar socio-cultural characteristics and unique in other health-related characteristics like access to health care, environment, housing system etc.

\section{Data collection}

The Demographic and Health Surveys (DHS) and alike surveys that collect information on birth outcomes from women are one of the main bases for data collection on under-five mortality estimation in developing countries like Nigeria, where reliable and adequate vital registration system is lacking [17]. The 2013 Nigeria Demographic and Health Survey data were used for this study. The original data was collected to provide information on the population, health and fertility levels in Nigeria. A 3-stage stratified cluster design consisting of 904 clusters (372 in urban areas and 532 in rural areas) was used for sample selection. A representative sample of 40,680 households was selected for the survey and a fixed sample of 45 households was selected in each cluster. In this study, the sample used was 18,516 women of reproductive age who had given birth in the past 5 years prior the survey. However, the attention was focused on the survival status of the index child, the most recent delivery the women had in the past 5 years prior the study.

\section{Variable description}

The dependent variable was childhood mortality and this was captured with the question on the survival status of the most recent birth (dead $=1$ or alive $=0)$ in the last 5 years preceding the survey. Under-five mortality was defined as the death of a live-born child before its fifth birthday [27]. The main predictor was the type of housing materials. This was obtained as aggregate score based on information from roof materials (Improved cement, roofing sheets, ceramic tiles; Unimproved - natural, no roof, palm leaf, sod, rudimentary, rustic mat, bamboo, cardboard), wall materials (Improved - cement, stone with cement, cement blocks, bricks; Unimproved - natural, no wall, palm/trunks, dirt, rudimentary, bamboo with mud) and floor materials (Improved - cement, ceramic tiles, vinyl asphalt strips, parquet, polished wood, finished; Unimproved - natural, earth, sand, dung, rudimentary, wood planks, palm, bamboo, others). The improved categories assumed a score of 1 while unimproved scored [36, 38]. The overall score (13-point maximum and 0-point minimum) for a woman was disaggregated into three categories: inadequate $(<50 \%$ of the overall score), moderate $(50 \% \leq x<75 \%$ of the overall score) and adequate $(75 \% \leq x \leq 100 \%)$ of the overall score). They are based on quartile classification: 3rd quartile is $75 \%$ and 2 nd quartile is $50 \%$.

Other independent variables include mother's age, highest educational level, religion, ethnicity, marital status, place of residence, region, wealth index and media exposure. others are; number of antenatal visits, tetanus injection, gender of a child, size at birth, birth order, preceding birth interval, prenatal care provider, delivery assistance, place of delivery, cooking fuel (Clean - electricity, liquefied petroleum gas, natural gas, biofuel; Unclean/biomass - coal, charcoal, wood, straw/shrubs/grass, agricultural crop, animal dung, kerosene), source of water (Improved - piped into dwelling, public tap, borehole, protected well and spring, rain water and bottle water; Unimproved - other sources not listed as improved sources) and toilet facility (Improved - flush/pour flush to piped sewer system, septic tank or pit latrine, ventilated improved pit latrine, pit latrine with slab, composting toilet; Unimproved - other toilet types not listed as improved). We adapted the groupings of environmental factors documented in the 2013 Nigeria National Demographic Health Survey (NDHS) and the 2010 WHO and UNICEF document on progress on sanitation and drinking water [36, 39]. These variables were used as covariates during multivariate analysis to determine the association between housing materials and childhood mortality.

\section{Data analyses}

The dataset was weighted before data analyses. The weight is an inflation factor which extrapolates the sample to the target population [40]. Analysis of data was done at bivariate and multivariate levels using Chisquare, Cox proportional hazard model and Brass 2parameter model. The Chi-square test was used to examine the relationship between child's survival status and the independent variables at 5.0\% level of significance. At the multivariate level of analysis, Cox proportional hazard model was used to detect the predictors of childhood mortality. The proportional hazards model assumes that the time to event and the covariates are related as; $\log _{\mathrm{e}}\left\{\frac{\gamma_{\mathrm{i}}(\mathrm{t})}{\gamma_{0}(\mathrm{t})}\right\}=\beta_{0}+\beta_{1} \mathrm{x}_{\mathrm{i} 1}+\beta_{2} \mathrm{x}_{\mathrm{i} 2}+\ldots+\beta_{\mathrm{p}} \mathrm{x}_{\mathrm{ip}}$. Where; $\gamma_{i}(t)$ is the hazard rate for the $i^{\text {th }}$ case of a woman having lost her child before age five; $\gamma_{0}(t)$ is the baseline hazard at time $t$ when the death of the child occurs; $\beta_{j}$ is the value of the $j^{\text {th }}$ regression coefficient; $x_{i j}$ is the value of the $i^{\text {th }}$ case of the $j^{\text {th }}$ covariate. 
Further analysis using an indirect method to ascertain the influence of housing materials on childhood mortality was done. Brass [41] reported that the probability of dying between birth and exact age (a) can be estimated as $\mathrm{q}(\mathrm{x})=\mathrm{k}(\mathrm{x}) \times \mathrm{D}(\mathrm{x})$ where $\mathrm{D}(\mathrm{x})$ is the number of dead children in each age group and $\mathrm{k}(\mathrm{x})$ is a multiplier and is estimated as; $\mathrm{k}(\mathrm{x})=\mathrm{a}(\mathrm{i})+\mathrm{b}(\mathrm{i})\left(\mathrm{P}_{1} / \mathrm{P}_{2}\right)+\mathrm{C}(\mathrm{i})\left(\mathrm{P}_{2} / \mathrm{P}_{3}\right)$. The number of non-surviving children for women in age groups 15-20, 20-25, 25-30,.., 45-50 were used to calculate childhood mortality at exact ages $(\mathrm{q}(\mathrm{x})) ; 1,2,3$, 5, 10, 15 and 20. Regression equations which relate the multipliers $\mathrm{k}(\mathrm{x})$ to indices of fertility schedule were formulated from mathematical simulations [42]. The time reference to which the $\mathrm{q}(\mathrm{x})$ values refer were also formulated. Due to limitations in the estimates produced by this method, we further adjusted the childhood mortality using Brass 1-parameter model $\left(Y=\alpha+\beta Y_{s}\right)$ where $\beta=1$. This procedure made use of logit equation: logit $\{\mathrm{q}(\mathrm{x})\}=\frac{1}{2} \log \left\{\frac{1-\mathrm{l}_{\mathrm{x}}}{\mathrm{l}_{\mathrm{x}}}\right\}$. This was transformed to Brass relational system of life tables; $\operatorname{logit}\{1(\mathrm{x})\}=\alpha+\beta \operatorname{logit}\left\{\mathrm{l}_{\mathrm{s}}(\mathrm{x})\right\}$ usually transcribed as $\mathrm{Y}=\alpha+\beta \mathrm{Y}_{\mathrm{s}}$. The logit relational system smoothens the estimated values of $\mathrm{l}(\mathrm{x})$ (survival probability) in contrast to the values from the model life-table. Therefore, if $\beta=1, \hat{\alpha}=\mathrm{Y}(\mathrm{x})-\mathrm{Y}_{\mathrm{s}}(\mathrm{x})$, thus generating; $\mathrm{Y}(1)=\hat{\alpha}_{1}+\mathrm{Y}_{\mathrm{s}}(1) ; \mathrm{Y}(2)=\hat{\alpha}_{2}+\mathrm{Y}_{\mathrm{s}}(2) ; \ldots ; \mathrm{Y}$ $(20)=\hat{\alpha}_{20}+Y_{s}(20)$. Estimate of $\hat{\alpha}$ was obtained from the average values of $x=2, x=3$ and $x=5$ which produce reliable values of $l(x)$. Therefore, if $\bar{Y}$ is the average of $\mathrm{Y}(2), \mathrm{Y}(3)$ and $\mathrm{Y}(5)$ and $\bar{Y}_{\mathrm{s}}$ is the average of $Y_{s}(2), Y_{s}(3)$ and $Y_{s}(5)$, then $\widehat{\hat{\alpha}}=\bar{Y}-\bar{Y}_{s}$. This produced the adjusted survival probabilities at childhood. The infant and under-five mortality were estimated using the models; infant mortality rate $=\frac{\mathrm{q}_{0}}{1-0.7 \times \mathrm{q}_{0}}$ and under5 mortality rate $=\frac{2 q_{5}}{2 \times\left(1-q_{5}\right)}$ [43].

All analysis were done using SPSS version 20.0 and Excel software.

\section{Results}

In Table 1, the data shows that the percentage of women whose most recent under-five children died was highest among women aged 35-49 years (7.2\%) and least between the age segment 25-34 years (4.7\%) $p<0.001$. The percentage of women who had lost their most recent child reduces with increasing level of education, increasing wealth quintile and level of media exposure. For instance, women who had high exposure to media had $4.5 \%$ deaths of their most recent under-five child compared to $6.7 \%$ reported by those with no media exposure.

Table 2 shows the results of the association between under-five survival status and maternal and child health-
Table 1 Socio-demographic characteristics of women according to deaths of under-five children

\begin{tabular}{|c|c|c|c|c|}
\hline $\begin{array}{l}\text { Background } \\
\text { characteristics }\end{array}$ & $\begin{array}{l}\text { Death among } \\
\text { under-5 children (\%) }\end{array}$ & $\begin{array}{l}\text { Total number } \\
\text { of children }\end{array}$ & $x^{2}$-value & $p$-value \\
\hline Mother's Age ${ }^{a}$ & & & 40.10 & $<0.001$ \\
\hline $15-24$ & 5.9 & 4746 & & \\
\hline $25-29$ & 4.7 & 4843 & & \\
\hline $30-34$ & 4.7 & 3830 & & \\
\hline $35-49$ & 7.2 & 5097 & & \\
\hline $\begin{array}{l}\text { Highest educational } \\
\text { level }^{\mathrm{a}}\end{array}$ & & & 48.97 & $<0.001$ \\
\hline No education & 6.7 & 8532 & & \\
\hline Primary & 6.1 & 3747 & & \\
\hline Secondary & 4.3 & 5038 & & \\
\hline Higher & 3.2 & 1199 & & \\
\hline Religion ${ }^{a}$ & & & 4.73 & 0.094 \\
\hline Christian & 5.3 & 7568 & & \\
\hline Islam & 6.0 & 10752 & & \\
\hline Others & 5.5 & 200 & & \\
\hline Ethnicity $^{a}$ & & & 34.42 & $<0.001$ \\
\hline Hausa & 6.6 & 7234 & & \\
\hline Igbo & 6.1 & 1916 & & \\
\hline Yoruba & 3.5 & 2236 & & \\
\hline Others & 5.3 & 7130 & & \\
\hline Marital status ${ }^{\mathrm{b}}$ & & & 11.15 & 0.004 \\
\hline Never in union & 6.9 & 492 & & \\
\hline $\begin{array}{l}\text { Currently in union/ } \\
\text { living with a man }\end{array}$ & 5.6 & 17445 & & \\
\hline Formerly in union & 8.6 & 579 & & \\
\hline \multicolumn{5}{|l|}{ Place of residence ${ }^{a}$} \\
\hline Urban & 4.0 & 6157 & & \\
\hline Rural & 6.5 & 12359 & & \\
\hline Geopolitical zones $^{\mathrm{a}}$ & & & 48.66 & $<0.001$ \\
\hline North Central & 4.2 & 2783 & & \\
\hline North East & 6.3 & 3692 & & \\
\hline North West & 6.9 & 5816 & & \\
\hline South East & 6.6 & 1568 & & \\
\hline South South & 5.1 & 2179 & & \\
\hline South West & 3.8 & 2478 & & \\
\hline Media exposure ${ }^{a}$ & & & 26.55 & $<0.001$ \\
\hline None & 6.7 & 6318 & & \\
\hline Low & 5.7 & 6013 & & \\
\hline Medium & 4.6 & 4607 & & \\
\hline High & 4.5 & 1578 & & \\
\hline
\end{tabular}

${ }^{\mathrm{a}}$ Significant at $0.1 \%$; ${ }^{\mathrm{b}}$ Significant at $1.0 \%$

related characteristics. Under-five deaths was highest among women who did not attend any antenatal clinic during the child's pregnancy (6.9\%), who did not take 
Table 2 Maternal and child health related characteristics according to deaths of under-five children

\begin{tabular}{|c|c|c|c|c|}
\hline $\begin{array}{l}\text { Background } \\
\text { characteristics }\end{array}$ & $\begin{array}{l}\text { Death among } \\
\text { under-5 children (\%) }\end{array}$ & $\begin{array}{l}\text { Total number } \\
\text { of children }\end{array}$ & $x^{2}$-value & $p$-value \\
\hline $\begin{array}{l}\text { Number of antenatal } \\
\text { visits }^{\mathrm{a}}\end{array}$ & & & 30.62 & $<0.001$ \\
\hline None & 6.9 & 6266 & & \\
\hline $1-3$ & 6.0 & 2346 & & \\
\hline $4+$ & 4.9 & 9904 & & \\
\hline Tetanus injection $^{a}$ & & & 29.68 & $<0.001$ \\
\hline None & 6.8 & 7362 & & \\
\hline At least 1 & 4.9 & 11154 & & \\
\hline Sex of child ${ }^{a}$ & & & 8.47 & 0.004 \\
\hline Male & 6.2 & 9347 & & \\
\hline Female & 5.2 & 9169 & & \\
\hline $\begin{array}{l}\text { Perceived size of baby } \\
\text { at birth }^{\mathrm{a}}\end{array}$ & & & 26.53 & $<0.001$ \\
\hline Small & 7.7 & 2738 & & \\
\hline Average & 5.6 & 7500 & & \\
\hline Larger than average & 5.1 & 8278 & & \\
\hline Birth order ${ }^{a}$ & & & 61.86 & $<0.001$ \\
\hline 1 st & 6.2 & 3302 & & \\
\hline $2-3$ & 4.3 & 5707 & & \\
\hline $4-5$ & 5.0 & 4416 & & \\
\hline $6+$ & 7.6 & 5091 & & \\
\hline Preceding birth interval & & & 28.25 & $<0.001$ \\
\hline $7-23$ & 7.2 & 2860 & & \\
\hline $24-35$ & 5.8 & 5775 & & \\
\hline $36-59$ & 4.6 & 4794 & & \\
\hline $60+$ & 4.7 & 1743 & & \\
\hline 1st birth & 6.4 & 3344 & & \\
\hline Prenatal care provider ${ }^{a}$ & & & 43.25 & $<0.001$ \\
\hline None & 6.9 & 6266 & & \\
\hline Unskilled & 9.1 & 176 & & \\
\hline Semi-skilled & 7.0 & 1434 & & \\
\hline Skilled & 4.8 & 10640 & & \\
\hline Delivery assistance ${ }^{a}$ & & & 36.52 & $<0.001$ \\
\hline None & 6.9 & 2264 & & \\
\hline Unskilled & 6.4 & 8385 & & \\
\hline Semi-skilled & 6.0 & 1092 & & \\
\hline Skilled & 4.4 & 6775 & & \\
\hline Place of delivery ${ }^{a}$ & & & 28.060 & $<0.001$ \\
\hline Home & 6.4 & 11503 & & \\
\hline Others & 3.3 & 30 & & \\
\hline Health facility & 4.6 & 6983 & & \\
\hline
\end{tabular}

${ }^{a}$ Significant at $0.1 \%$ any tetanus injection (6.8\%), whose prenatal care was provided by unskilled attendant $(9.1 \%)$, who were not assisted by any attendant during delivery (6.9\%) and those who delivered at their homes (6.4\%).

The percentage of the most recent under-five children who had died was higher among males (6.2\%) than female $(5.2 \%)(p<0.001)$.

The preceding birth interval was also found to be significantly associated with under-five death with children whose their immediate senior sibling was born 7-23 months (7.2\%) before their delivery experiencing highest deaths compared to those who left 24-35 months (5.8\%), 36-59 months (4.6\%) interval. Figure 1 shows the percentage distribution of under-deaths by building material assessment score.

The data as represented in Table 3 show that the type of cooking fuel, the source of drinking water, toilet facility and housing materials were significantly associated with childhood deaths $(p<0.05)$. However, variation exists in childhood deaths within these environmental factors. For example, women who used biomass had experienced higher under-five deaths (6.1\%) than those using clean fuel (3.8\%). Under-five death was lower among children of women who used improved sources (5.2\%) as their drinking and cooking water than their counterparts using unimproved sources $(6.3 \%)$. This pattern was similar to that of the improved and unimproved toilet facility. The results further show that women who lived in houses built with inadequate housing materials (7.1\%) lost more of their under-five children compared to those who lived in houses built with adequate housing materials $(4.4 \%)(p<0.001)$.

\section{Multivariate results}

At the multivariate level of analysis, as shown in Table 4, four models were generated. The first model included only the key independent variable (Housing materials) while the housing materials and other environmental factors were included in the second model. The third model involved the housing materials, other environmental factors and health/child-related factors while the socio-demographic and all other factors were included in the last model. The models were built in this manner so as to explore the possible interaction of the housing material and childhood mortality while other factors were used as covariates.

The data revealed that the type of housing materials was significantly associated with childhood mortality across the first three models. For instance, in model 1, the hazard ratio of childhood mortality was 1.23 (C.I = $1.24-1.71, p<0.001)$ and $1.46(\mathrm{C} . \mathrm{I}=1.02-1.47, p<0.001)$ higher among children who lived in houses built with moderate and inadequate housing materials respectively than those living in houses built with adequate housing 


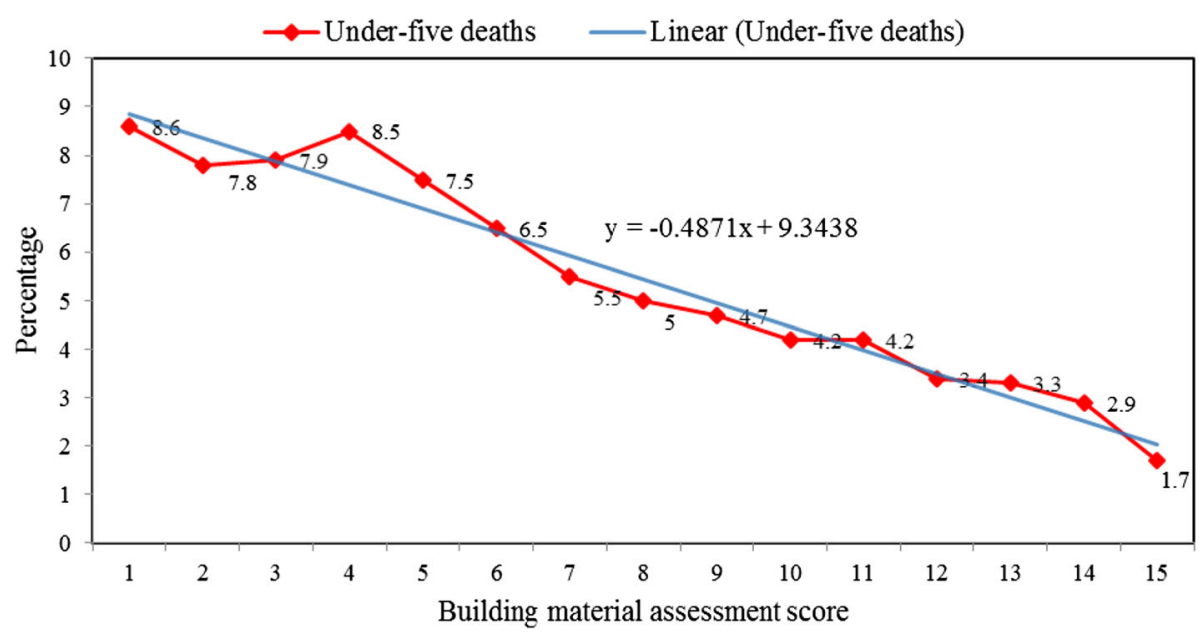

Fig. 1 Percentage distribution of under-deaths by housing material assessment score. It presents a downward trend (slope $=-0.4871$ ) in the percentage distribution of childhood deaths according to the building materials assessment score with highest and least proportion of under-five children found among those who live in a house with 1 and 13 building assessment scores respectively

materials. This pattern was found across the models but in the last model, housing materials were found to be insignificantly associated with childhood mortality showing that socio-demographic factors are strongly important in the relationship between childhood mortality and housing materials. The identified predictors of childhood mortality are; the size of the child at birth, preceding birth interval, prenatal care provider, place of residence and education. The likelihood of childhood mortality was 0.82 (C.I $=0.72-0.92 ; p<0.001$ ) lower among females than males, among children who were average $(\mathrm{HR}=0.76$; C.I $=0.64-0.90)$ or larger $(\mathrm{HR}=0.71 ; \mathrm{C} . \mathrm{I}=0.60-0.84$,

Table 3 Environmental characteristics according to deaths of under-five children

\begin{tabular}{|c|c|c|c|c|}
\hline $\begin{array}{l}\text { Environmental } \\
\text { characteristics }\end{array}$ & $\begin{array}{l}\text { Death among } \\
\text { under-5 children (\%) }\end{array}$ & $\begin{array}{l}\text { Total number } \\
\text { of children }\end{array}$ & $x^{2}$-value & $p$-value \\
\hline Cooking fuel $^{a}$ & & & 28.25 & $<0.001$ \\
\hline Clean & 3.8 & 3340 & & \\
\hline Biomass & 6.1 & 15176 & & \\
\hline \multicolumn{2}{|c|}{ Source of drinking water ${ }^{a}$} & & 9.64 & 0.002 \\
\hline Improved & 5.2 & 10339 & & \\
\hline Unimproved & 6.3 & 8177 & & \\
\hline Toilet facility $^{a}$ & & & 11.47 & 0.001 \\
\hline Improved & 5.1 & 9090 & & \\
\hline Unimproved & 6.3 & 9426 & & \\
\hline Housing material $^{\mathrm{a}}$ & & & 50.91 & $<0.001$ \\
\hline Inadequate & 7.1 & 7035 & & \\
\hline Moderate & 5.9 & 3414 & & \\
\hline Adequate & 4.4 & 8067 & & \\
\hline
\end{tabular}

${ }^{\mathrm{a}}$ Significant at $0.1 \%$ $p<0.001)$ than average in size at birth than those who were small. The data further show that childhood mortality hazard was 1.35 (C.I $=1.13-1.62, p<0.001)$ more in the rural areas than the urban.

\section{Infant and under-five mortality rates by housing material type}

In Table 5, the data show that at different levels of housing materials type (inadequate, moderate and adequate), the refined childhood mortality probability estimate increases as the age of child increases. For instance, among the group of women who live in houses built with inadequate housing material, the refined childhood mortality probability increases from 0.0778 among infants to 0.1613 among young adults. The data further show that infant mortality probability increases considerably as the level of housing materials type increases.

For instance, the probability of dying at exact age 1 year was highest among women who live in houses built with inadequate housing materials (0.0778) and least among their counterparts whose houses were built with adequate materials (0.0507). Figure 2 shows childhood probability of dying at age $\mathrm{x}$ according to housing materials. The estimated infant and under-five mortality rates which were obtained from the smoothed childhood mortality probabilities in Table 5 are displayed in Fig. 3.

\section{Discussion}

Housing and health are essential for human wellness and quality of life [44]. Poor housing conditions have been seen to represent a stern environmental health threat that is preventable [45]. Our study seeks to understand the effect of housing materials on under-five mortality in Nigeria. 
Table 4 Cox proportional hazard model of determinants of childhood mortality in Nigeria

\begin{tabular}{|c|c|c|c|c|}
\hline \multirow[t]{2}{*}{ Background characteristics } & Model 1 & Model 2 & Model 3 & Model 4 \\
\hline & HR (95\% CloHR) & HR (95\% CloHR) & HR (95\% CloHR) & HR (95\% CloHR) \\
\hline \multicolumn{5}{|l|}{ Housing material $^{a}$} \\
\hline Inadequate & $1.46(1.24-1.71)^{\mathrm{a}}$ & $1.36(1.16-1.60)^{\mathrm{a}}$ & $1.25(1.05-1.49)^{b}$ & $1.03(0.82-1.27)$ \\
\hline Moderate & $1.23(1.02-1.47)^{\mathrm{a}}$ & $1.20(1.03-1.44)^{b}$ & $1.14(0.94-1.37)$ & $0.94(0.74-1.18)$ \\
\hline Adequate & 1 & 1 & 1 & 1 \\
\hline \multicolumn{5}{|l|}{ Sex of the child } \\
\hline Male & & 1 & 1 & 1 \\
\hline Female & & $0.82(0.72-0.92)^{a}$ & $0.82(0.72-0.92)^{\mathrm{a}}$ & $0.80(0.69-0.92)^{b}$ \\
\hline \multicolumn{5}{|l|}{ Size at birth } \\
\hline Small & & 1 & 1 & 1 \\
\hline Average & & $0.76(0.64-0.89)^{a}$ & $0.76(0.64-0.90)^{\mathrm{a}}$ & $0.81(0.66-0.98)^{c}$ \\
\hline Larger than average & & $0.69(0.52-0.81)^{\mathrm{a}}$ & $0.70(0.59-0.83)^{a}$ & $0.77(0.63-0.93)^{b}$ \\
\hline \multicolumn{5}{|l|}{ Prenatal care provider } \\
\hline None & & & $1.11(0.87-1.40)$ & $1.07(0.81-1.40)$ \\
\hline Unskilled & & & $1.78(1.06-2.98)^{\mathrm{b}}$ & $1.95(0.99-3.82)$ \\
\hline Semi-skilled & & & $1.23(0.97-1.57)$ & $1.28(0.97-1.69)$ \\
\hline Skilled & & & 1 & 1 \\
\hline \multicolumn{5}{|l|}{ Delivery assistance } \\
\hline None & & & $1.14(0.79-1.66)$ & $0.93(0.58-1.48)$ \\
\hline Unskilled & & & $1.17(0.83-1.65)$ & $0.96(0.62-1.48)$ \\
\hline Semi-skilled & & & $1.14(0.83-1.57)$ & $0.83(0.55-1.23)$ \\
\hline Skilled & & & 1 & 1 \\
\hline \multicolumn{5}{|l|}{ Tetanus injection } \\
\hline None & & & $1.05(0.86-1.29)$ & $1.04(0.82-1.32)$ \\
\hline At least one & & & 1 & 1 \\
\hline \multicolumn{5}{|l|}{ Number of antenatal visits } \\
\hline None & & & $1.01(0.32-1.35)$ & $1.02(0.31-1.39)$ \\
\hline $1-3$ & & & $1.05(0.86-1.28)$ & $1.05(0.83-1.32)$ \\
\hline $4+$ & & & 1 & 1 \\
\hline \multicolumn{5}{|l|}{ Toilet facility } \\
\hline Improved & 1 & 1 & 1 & 1 \\
\hline Unimproved & $1.04(0.92-1.19)$ & $1.05(0.92-1.20)$ & $1.04(0.91-1.19)$ & $1.14(0.97-1.33)$ \\
\hline \multicolumn{5}{|l|}{ Birth order } \\
\hline $1 s t$ & & 1 & 1 & 1 \\
\hline $2-3$ & & $3.80(1.94-7.42)^{a}$ & $3.80(1.94-7.42)^{\mathrm{a}}$ & $3.61(1.46-8.88)^{b}$ \\
\hline $4-5$ & & $4.44(2.21-8.89)^{\mathrm{a}}$ & $4.44(2.21-8.89)^{\mathrm{a}}$ & $3.80(1.49-9.68)^{b}$ \\
\hline $6+$ & & $6.47(3.24-12.91)^{\mathrm{a}}$ & $6.47(3.24-12.91)^{\mathrm{a}}$ & $4.93(1.92-12.60)^{b}$ \\
\hline \multicolumn{5}{|l|}{ Cooking fuel } \\
\hline Clean & 1 & 1 & 1 & 1 \\
\hline Biomass & $1.31(1.06-1.62)^{\mathrm{a}}$ & $1.22(0.99-1.51)^{b}$ & $1.16(0.94-1.44)$ & $0.81(0.56-1.18)$ \\
\hline \multicolumn{5}{|l|}{ Place of delivery } \\
\hline Home & & & 1 & 1 \\
\hline Others & & & $0.94(0.68-1.29)$ & $0.71(0.09-5.11)$ \\
\hline Health facility & & & $0.47(0.65-3.44)$ & $1.11(0.74-1.66)$ \\
\hline
\end{tabular}


Table 4 Cox proportional hazard model of determinants of childhood mortality in Nigeria (Continued)

$$
\begin{gathered}
\text { Age group } \\
15-24 \\
25-29 \\
30-34 \\
35-39
\end{gathered}
$$

Source of drinking water

$\begin{array}{ll}\text { Improved } & 1 \\ \text { Unimproved } & 1.05(0.93-1.20)\end{array}$

Geopolitical zones

$$
\text { North Central }
$$$$
\text { North East }
$$

North West

South East

South South

South West

Preceding birth interval

$\begin{array}{ll}7-23 & 1 \\ 24-35 & 0.81(0.68-0.96)^{\mathrm{b}} \\ 36-59 & 0.64(0.53-0.77)^{\mathrm{a}} \\ 60+ & 0.69(0.53-0.89)^{\mathrm{a}} \\ \text { 1st birth } & 4.39(2.23-8.63)^{\mathrm{a}}\end{array}$

Place of Residence

Urban

Rural

Highest educational level

None

Primary

Secondary

Tertiary

Ethnicity

Hausa/Fulani

Igbo

Yoruba

Others

Media exposure

None

Low

Medium

High

Marital status

Never in union

Currently in union

Formerly in union
1

$1.04(0.92-1.19)$

1

$0.97(0.76-1.22)$

$0.95(0.71-1.26)$

$1.20(0.89-1.62)$

\section{1}

$1.02(0.90-1.17)$
$1.02(0.88-1.18)$

$1.13(0.69-1.84)$

$1.57(0.96-2.55)$

$1.85(1.11-3.05)^{\mathrm{c}}$

$2.54(0.87-7.37)$

$1.29(0.77-2.13)$

1

$0.82(0.67-0.99)^{\mathrm{c}}$

$0.64(0.51-0.79)^{a}$

$0.57(0.41-0.79)^{b}$

$3.91(1.57-9.70)^{b}$

1

$1.23(0.87-2.54)$

$1.73(0.85-3.52)$

$1.94(0.96-3.89)$

$1.51(0.76-2.96)$

1

$0.99(0.79-1.25)$

$0.69(0.26-1.79)$

$0.82(0.46-1.45)$

$0.97(0.82-1.14)$

$1.05(0.82-1.33)$

$1.01(0.62-1.61)$

HR hazard ratio, $\mathrm{ClOHR}$ confidence interval of hazard ratio

${ }^{a}$ Significant at $0.1 \%$; ${ }^{b}$ Significant at $1.0 \%$; ${ }^{c}$ Significant at $5.0 \%$ 
Table 5 Estimated smoothed childhood mortality probability according to housing materials type, 2013 Nigeria demographic and health survey

\begin{tabular}{|c|c|c|c|c|c|c|c|c|c|c|}
\hline Age group & $\mathrm{Pi}$ & $\mathrm{Di}$ & Age $x$ & $I(\mathrm{X})_{\mathrm{ES}}$ & $/(\mathrm{x})_{\mathrm{Br}}$ & $Y(x)$ & $Y(s)$ & Adj. $Y(x)$ & Adj. $q(x)$ & Ref. period \\
\hline \multicolumn{11}{|c|}{ 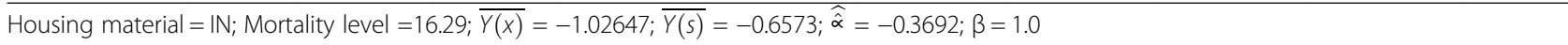 } \\
\hline $15-19$ & 1.24 & 0.1156 & 1 & 1.00015 & 0.91303 & -1.1756 & -0.8670 & -1.2362 & 0.0778 & 2010.4 \\
\hline $20-24$ & 2.13 & 0.1426 & 2 & 0.88676 & 0.89479 & -1.0703 & -0.7152 & -1.0844 & 0.1026 & 2008.9 \\
\hline $25-29$ & 3.77 & 0.1793 & 3 & 0.82322 & 0.88651 & -1.0278 & -0.6552 & -1.0244 & 0.1142 & 2007.8 \\
\hline $30-34$ & 5.36 & 0.1985 & 5 & 0.78822 & 0.87682 & -0.9813 & -0.6015 & -0.9707 & 0.1255 & 2007.1 \\
\hline $35-39$ & 6.90 & 0.2222 & 10 & 0.75241 & 0.86552 & -0.9309 & -0.5498 & -0.9190 & 0.1373 & 2006.6 \\
\hline $40-44$ & 8.01 & 0.2362 & 15 & 0.73754 & 0.85705 & -0.8955 & -0.5131 & -0.8823 & 0.1462 & 2005.5 \\
\hline $45-49$ & 9.43 & 0.2711 & 20 & 0.70206 & 0.84449 & -0.8460 & -0.4551 & -0.8243 & 0.1613 & 2003.0 \\
\hline \multicolumn{11}{|c|}{ Housing material $=\mathrm{MO} ;$ Mortality level $=16.98 ; \overline{Y(x)}=-1.08753 ; \overline{Y(s)}=-0.6573 ; \widehat{\hat{\alpha}}=-0.4302 ; \beta=1.0$} \\
\hline $15-19$ & 1.25 & 0.1476 & 1 & 1.005 & 0.92114 & -1.2289 & -0.867 & -1.2972 & 0.0695 & 2010.3 \\
\hline $20-24$ & 2.08 & 0.1309 & 2 & 0.89822 & 0.90553 & -1.1301 & -0.7152 & -1.1454 & 0.0919 & 2008.8 \\
\hline $25-29$ & 3.53 & 0.1657 & 3 & 0.83811 & 0.89828 & -1.0891 & -0.6552 & -1.0854 & 0.1024 & 2007.7 \\
\hline $30-34$ & 5.13 & 0.1772 & 5 & 0.81199 & 0.88961 & -1.0434 & -0.6015 & -1.0317 & 0.1127 & 2006.9 \\
\hline $35-39$ & 6.70 & 0.2012 & 10 & 0.77681 & 0.87945 & -0.9936 & -0.5498 & -0.9800 & 0.1235 & 2006.3 \\
\hline $40-44$ & 7.54 & 0.1895 & 15 & 0.79033 & 0.87179 & -0.9585 & -0.5131 & -0.9433 & 0.1316 & 2005.3 \\
\hline $45-49$ & 9.04 & 0.2052 & 20 & 0.77545 & 0.86030 & -0.9089 & -0.4551 & -0.8853 & 0.1455 & 2002.8 \\
\hline \multicolumn{11}{|c|}{ Housing material $=A D ;$ Mortality level $=18.68 ; \overline{Y(X)}=-1.2556 ; \overline{Y(s)}=-0.6573 ; \widehat{\hat{\alpha}}=-0.5983 ; \beta=1.0$} \\
\hline $15-19$ & 1.22 & 0.0921 & 1 & 1.01869 & 0.93998 & -1.3756 & -0.8670 & -1.4653 & 0.0507 & 2010.0 \\
\hline $20-24$ & 1.79 & 0.1044 & 2 & 0.92512 & 0.93007 & -1.2939 & -0.7152 & -1.3135 & 0.0674 & 2008.3 \\
\hline $25-29$ & 2.74 & 0.1127 & 3 & 0.89233 & 0.92520 & -1.2576 & -0.6552 & -1.2535 & 0.0754 & 2007.1 \\
\hline $30-34$ & 3.90 & 0.1151 & 5 & 0.87886 & 0.91914 & -1.2153 & -0.6015 & -1.1998 & 0.0832 & 2006.4 \\
\hline $35-39$ & 5.24 & 0.1418 & 10 & 0.84323 & 0.91172 & -1.1674 & -0.5498 & -1.1481 & 0.0914 & 2006.0 \\
\hline $40-44$ & 6.33 & 0.1495 & 15 & 0.83494 & 0.90606 & -1.1332 & -0.5131 & -1.1114 & 0.0977 & 2005.1 \\
\hline $45-49$ & 7.44 & 0.1551 & 20 & 0.83069 & 0.89718 & -1.0831 & -0.4551 & -1.0534 & 0.1084 & 2002.7 \\
\hline \multicolumn{11}{|c|}{ Housing material $=$ Total; Mortality level $=16.95 ; \overline{Y(x)}=-1.08477 ; \overline{Y(s)}=-0.6573 ; \widehat{\hat{\alpha}}=-0.4275 ; \beta=1.0$} \\
\hline $15-19$ & 1.24 & 0.1184 & 1 & 1.00248 & 0.92078 & -1.2265 & -0.8670 & -1.2945 & 0.0699 & 2010.4 \\
\hline $20-24$ & 2.08 & 0.1310 & 2 & 0.89781 & 0.90506 & -1.1274 & -0.7152 & -1.1427 & 0.0923 & 2008.8 \\
\hline $25-29$ & 3.53 & 0.1613 & 3 & 0.84245 & 0.89777 & -1.0863 & -0.6552 & -1.0827 & 0.1029 & 2007.7 \\
\hline $30-34$ & 5.03 & 0.1741 & 5 & 0.81548 & 0.88905 & -1.0406 & -0.6015 & -1.0290 & 0.1133 & 2006.9 \\
\hline $35-39$ & 6.55 & 0.1975 & 10 & 0.78121 & 0.87884 & -0.9907 & -0.5498 & -0.9773 & 0.1241 & 2006.3 \\
\hline $40-44$ & 7.64 & 0.2065 & 15 & 0.77185 & 0.87115 & -0.9556 & -0.5131 & -0.9406 & 0.1323 & 2005.2 \\
\hline $45-49$ & 8.85 & 0.2358 & 20 & 0.74232 & 0.85961 & -0.9060 & -0.4551 & -0.8826 & 0.1462 & 2002.7 \\
\hline
\end{tabular}

$P(i)$ Parity, $D(i)$ proportion of children dead, $q(x)$ probability of dying, $I(x)$ probability of surviving, MHCSAl maternal health care service access index, ES estimated, $B r$ brass, Ref. reference, $\overline{Y(x)} \operatorname{logit}(\mathrm{x}), \overline{Y(s)} \operatorname{logit}(\mathrm{s}), \overline{\bar{\alpha}}$ Mean of estimated parameter $\alpha, I N$ inadequate, $M O$ moderate, $A D$ adequate

Findings from our study show that the risk of dying before the age of 5 years was higher among children who lived in houses built with inadequate housing materials than those in moderate and adequate housing materials. This results gave credence to other studies that established an association between ill health and poor housing conditions [46-49]. The quality of the materials with which a building is built is mostly linked with the durability of the building and the health of its occupants [9]. Existing literature indicates general health improvements with improved housing conditions [50-52].
Izugbara [53], in his study, reported that households with floors made of mud or sand are more likely to experience under-5 mortality than households with cement residence floors.

Also, recent epidemiological studies revealed that living in houses built with inferior materials could result in chronic diseases $[54,55]$. Researchers assert that houses built with mud or sand are usually not durable and are prone to damp conditions which encourage the growth of moulds in an indoor environment [35]. Exposure to damp and mouldy housing could lead to the occurrence 


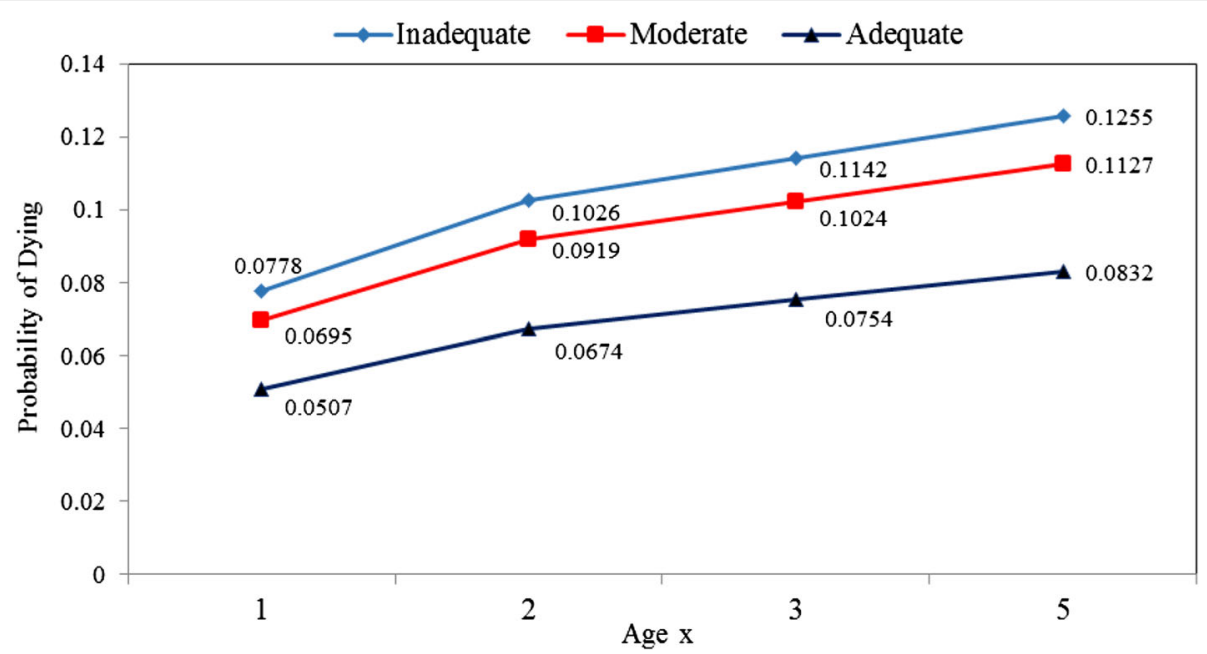

Fig. 2 Childhood probability of dying at age $x$ according to housing materials. It provides the pattern of the probability of dying at ages 1, 2, 3 and 5. There was a consistent increasing pattern in the probability of dying from ages 1 to 5 years and maternal housing materials type

of asthma and other chronic respiratory infections in children [54, 55]. Asthma is the most common noncommunicable disease among children, affecting 235 million people globally [56].

Moreover, damp buildings produce cracks on walls which provide a fostering environment for cockroaches, moulds, mites and respiratory viruses, all of which promote respiratory disease pathogenesis [35, 57]. Cockroaches can effect allergic sensitisation and have been seen to trigger asthma occurrence in urban areas. Children presenting with asthma who are sensitised and exposed to cockroaches are at higher risk of hospitalisation [58]. Also, exposure to pollutants such as formaldehyde and volcanic organic compounds, which are emitted from building materials have been associated with asthma, and bronchial obstruction in the first 24 months of life $[59,60]$. Our study revealed that women who used biomass, water from unimproved sources and unimproved toilet facilities had experienced higher under-five deaths than those using clean fuel, improved water sources and improved toilet facilities respectively. Indeed, the use of solid fuels in homes have been reported to be the leading single environmental cause of ill health [61-63]. Previous studies have indicated that children living in homes using solid fuels for cooking are at a greater risk of dying from acute respiratory illnesses [64-66]. According to the WHO [25], about half of all deaths among under-five children in the year 2014 was

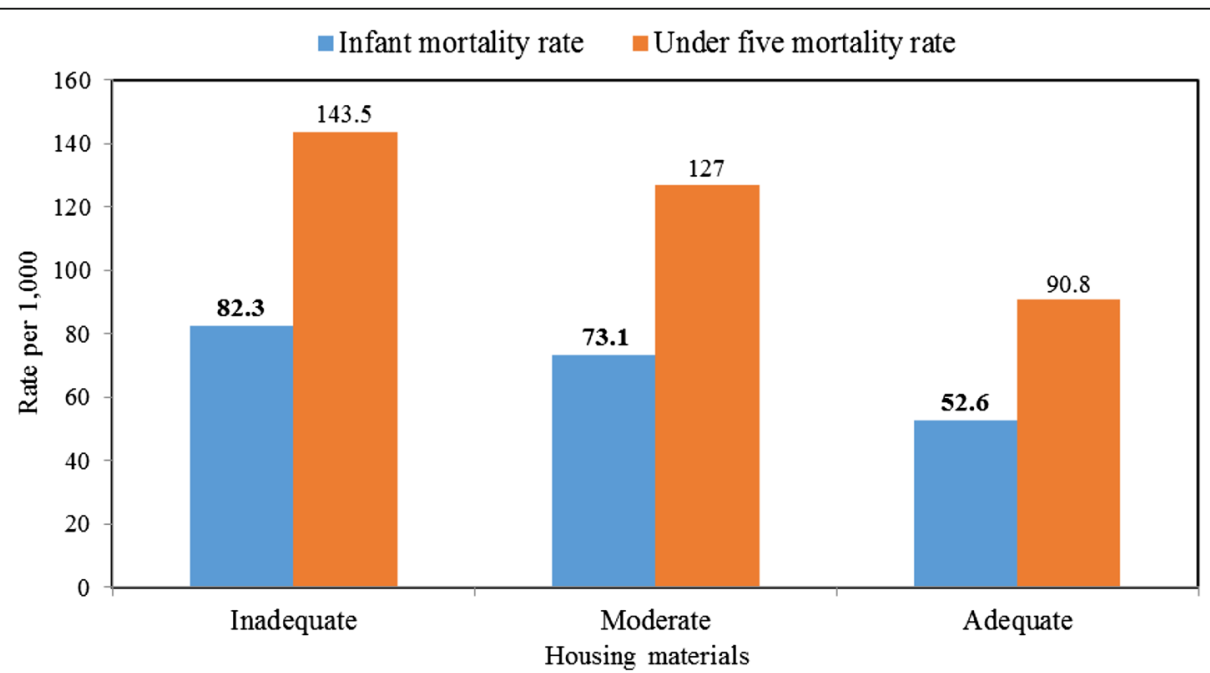

Fig. 3 Infant and Under-five mortality rates according to housing materials type. The data show that infant mortality rate reduces from 82.3 per 1000 live birth among women who live in houses built with inadequate housing materials to 52.6 per 1000 live birth among those live in houses built with adequate housing materials. This pattern was also observed for under-five mortality across the housing materials categories 
caused by acute lower respiratory infections triggered by the use of solid fuels.

Sourcing water from unimproved sources and poor sanitation practices have been implicated in the death of a child every $15 \mathrm{~s}$ from diarrhea disease [67]. According to the WHO, diarrhea, annually accounts for 1.7 million morbidities and 760, 000 under-five children's deaths globally [68]. It remains the second leading cause of death among children under-five globally [69].

This study further revealed that child and maternal characteristics such as sex the child, the size of the child at birth, preceding birth interval, prenatal care provider, place of residence and education, play a significant role in under-five mortality. This corroborated earlier findings from Nigeria and other places in the direction of these associations between under-five deaths and child and maternal characteristics [53, 64, 65, 70-77].

\section{Policy implication}

Globally, scientific evidence on the associations between housing and health has grown considerably in recent years. This information has been used as preventive measures that are linked to better housing condition and human health. From a policy point of view, there is a need for formulation of guidelines on healthy housing by the government and other relevant stakeholders to assist in averting a wide range of preventable illnesses that are often associated with poor housing conditions. This position has earlier been echoed at the international consultation of 40 specialists drafted from 18 countries by the WHO on 13-15 October 2010 in Geneva [78]. In this regard, a national standard on "healthy housing would enable action that is scientifically based, and protects and advances the health of under-five children in households" [78]. The existing national housing policy that sees housing as a determinant of health and social stability should be strengthened in Nigeria. However, the most healthy and safest house will not support the health of its inhabitants if not maintained and used in a manner that promotes sound health. Therefore, individuals should be advised to use good housing materials while building their houses. Even the poor can get good housing materials from the little resources they have if properly managed.

\section{Limitation}

The major shortcoming of this study is the cross-sectional nature of the data where information on housing materials was based on verbal reporting instead of the use of check listing approach which could have revealed the true state of housing condition in the study area. Although this limitation was minimized since data were collected at the individual homes, the data collectors were able to assess the structures and match their observations with the report from the respondents. Also, the reporting of under-five children's death by women may include omission of few dead children. Culturally, in sub-Saharan Africa, people dislike talking about their dead children as they see this as a bad event they don't want to remember. However, in this study, we used an indirect method that accounts for such limitation for the estimation of childhood mortality across the classes of housing materials.

\section{Conclusion}

The death of under-five children in the face of various factors remains a problem in Nigeria as the estimated infant and under-five mortality rates in this study are high. Living in houses built with inadequate housing materials promoted under-five mortality in Nigeria. Also, housing materials, environmental factors in addition to maternal and childhood characteristics were associated with childhood mortality. Housing materials remain a predictor of under-five mortality when environmental, child's characteristics and health-related factors were used as covariates. However, amidst all factors, housing materials may not be so important, instead maternal education, place of residence, sex, the size of the child at birth, prenatal care provider, birth order and preceding birth interval are the key predictors of deaths among under-five children in Nigeria. The existence of under-five mortality inequalities across different areas, regions and socioeconomic groups is also well documented. Various reforms and policies have been instituted by the government and relevant stakeholders to address the high rate of under-five mortality in Nigeria but these are yet to yield the expected results. Improvements in housing conditions and in the continuum of maternal and child health will play a significant role in reducing the burden of under-five mortality in Nigeria.

\section{Abbreviations \\ ARIs: Acute respiratory infections; C.I: Confidence interval; CloHR: Confidence interval of hazard; DHS: Demographic and health surveys; HR: Hazard ratio; MDGs: Millennium development goals; SDGs: Sustainable development goals; U5M: Under-five mortality; UNDESA: United Nations Department of Economic and Social Affairs; UNICEF: United Nations Children's Fund; VPD: Vaccines preventable diseases; WHO: World Health Organisation}

\section{Acknowledgements}

We are grateful to the National Population Commission and ICF Macro Calverton, Maryland, USA for releasing the data for this study. OMM acknowledge the technical support he received from the Consortium for Advanced Research Training in Africa (CARTA). OMM is a CARTA fellow and he received training in research conception and manuscript writing.

\section{Funding}

No funding was available for this study.

\section{Availability of data and materials}

The data that support the findings of this study are available from the MEASURE DHS but restrictions apply to the availability of these data, which were used under license for the current study, and so are not publicly available. Data are however available upon reasonable request and with permission of the MEASURE DHS through http://www.dhsprogram.com. 


\section{Authors' contributions}

ASA, OMM and AGR conceived the study, developed the research questions and designed the study. ASA analysed the data, wrote the methodology and the result sections. OMM wrote the introduction, discussion and part of the result sections. AGR took part in the writing of the introduction, discussion and critical revision of the manuscript for important intellectual content. All authors read and approved the final manuscript.

\section{Competing interests}

The authors declare that they have no competing interests.

\section{Consent for publication}

Not applicable.

\section{Ethics approval and consent to participate}

Ethical approval for this study was obtained by the data originators from the Nigeria National Ethics Committee (NHREC/2008/07), functioning under the Ministry of Health. An informed consent was obtained from all the study participants after describing to them all the issues related to the study in details at the point of data collection. Each consented participants was made to sign an appropriate agreement form before the interview.

\section{Author details}

'Department of Epidemiology and Medical Statistics, Faculty of Public Health, College of Medicine, University of Ibadan, Ibadan, Nigeria. ${ }^{2}$ Department of Environmental Health Sciences, Faculty of Public Health, College of Medicine, University of Ibadan, Ibadan, Nigeria.

Received: 4 February 2016 Accepted: 28 November 2016

\section{Published online: 19 January 2017}

\section{References}

1. Braubach M, Fairburn J. Social inequities in environmental risks associated with housing and residential location - a review of evidence. Euro J Public Health. 2010;20(1):36-42.

2. Lawrence RJ. Housing and health: from interdisciplinary principles to transdisciplinary research and practice. Futures. 2004:36:487-502.

3. Dunn JR. The population health approach to housing: a framework for research. A research report prepared for National Housing Research Committee. Canada Mortgage and Housing Corporation; 2002. http:// publications.gc.ca/collections/collection_2011/schl-cmhc/nh18-1-5/NH15394-2002-eng.pdf. Accessed 26 Mar 2012.

4. Krieger J, Higgins DL. Housing and health: time again for public health action. Am J Public Health. 2002:92:758-68.

5. US Department of Health and Human Services. The surgeon general's call to action to promote healthy homes. Rockville: US Department of Health and Human Services, Office of the Surgeon General; 2009. https://www. healthdata.gov/. Accessed 27 Apr 2016

6. Jacobs DE. Environmental health disparities in housing. J Am Public Health Assoc. 2011;101 Suppl 1:S115-22.

7. Hornberg C, Pauli A. Substandard housing: the social dimension of environmental health. Bielefeld: University of Bielefeld; 2011. p. 276-89.

8. Udofia EA, Yawson AE, Aduful KA, Bwambale FM. Residential characteristics as correlates of occupants' health in the Greater Accra Region, Rhana. BMC Public Health. 2014;14(244):1-13.

9. Alnsour J. Illegal housing in Jordan. Jordan J Soc Sci. 2011;4:339-54.

10. Rauh VA, Chew GL, Garfinkel RS. Deteriorated housing contributes to high cockroach allergen levels in inner-city households. Environ Health Perspect. 2002;110:323-7.

11. Rauh VA, Landrigan PJ, Claudio L. Housing and health: intersection of poverty and environmental exposures. Ann N Y Acad Sci. 2008;1136:276-88.

12. Fullilove MT, Fullilove RE. What's housing got to do with it? Am J Public Health. 2000;90:183-4

13. Thabethe NDL, Engelbrecht JC, Wright CY, Oosthuizen MA. Human health risks posed by exposure to PM10 for four life stages in a low socioeconomic community in South Africa. Pan Afr Med J. 2014;18:206. doi:10.11604/pamj.2014.18.206.3393

14. Wargocki P, Wyon DP. Providing better thermal and air quality conditions in school classrooms would be cost-effective. Build Environ. 2013;59:581-9.

15. Bearer CF. Environmental health hazards: how children are different from adults. Future Child. 1995;5(2):11-26.
16. WHO/UNICEF/World Bank group/United Nations. Levels \& Trends in Child Mortality. Report 2015 Estimates Developed by the UN Inter-agency Group for Child Mortality Estimation. http://www.childmortality.org/files_v20/ download/igme\%20report\%202015\%20child\%20mortality\%20final.pdf. Accessed 18 May 2016.

17. Pedersen J, Liu J. Child Mortality Estimation: Appropriate Time Periods for Child Mortality Estimates from Full Birth Histories. PLoS Med. 2012;9(8): e1001289. doi:10.1371/journal.pmed.1001289.

18. Fox J. Public health, poor relief and improving urban child mortality outcomes in the decade prior to the new deal. MPIDR Working Paper 2012; WP 2011-005. http://www.demogr.mpg.de/papers/working/wp-2011-005.pdf. Accessed 18 May 2016.

19. WHO. Children: reducing mortality. 2016. http://www.who.int/mediacentre/ factsheets/fs178/en/. Accessed 18 May 2016

20. WHO. World Health Statistics. Report 2014

21. Ezeh OK, Agho KE, Dibley MJ, Hall JJ, Page AN. Risk factors for post neonatal, infant, child and under-5 mortality in Nigeria: a pooled cross-sectional analysis. BMJ Open. 2015;5:e006779. doi:10.1136/bmjopen-2014-006779.

22. WHO/UNICEF. Progress on sanitation and drinking-water - 2014 update. Geneva: WHO/UNICEF; 2014

23. Adeyele IT, Ofoegbu DI. Infant and child mortality in nigeria: an impact analysis. Int J Econ Pract Theories. 2013;3(2):122-32.

24. Adepoju AO. Differential pattern in child mortality in Rural Nigeria. Annual Res Rev Biol. 2015;7(5):309-17.

25. WHO. Burden of disease from household air pollution for 2012. http://www who.int/phe/health_topics/outdoorair/databases/HAP_BoD_results_ March2014.pdf. Accessed 12 Jan 2016

26. Akinyemi JO, Adebowale AS, Bamgboye EA, Ayeni O. Child survival dynamics in Nigeria: Is the 2006 child health policy target met? Nigerian J Health Sci. 2015:15(1):18-26.

27. Adedini SA, Odimegwu C, Bamiwuye O, Fadeyibi O, De Wet N. Barriers to accessing health care in Nigeria: implications for child survival. Glob Health Action. 2014;7:23499. http://dx.doi.org/10.3402/gha.v7.23499.

28. Adedini SA, Odimegwu C, Imasiku EN, Ononokpono DN. Ethnic differentials in under-five mortality in Nigeria. Ethn Health. 2015;20(2):145-62.

29. Adedini SA, Odimegwu C, Imasiku EN, Ononokpono DN, Ibisomi L. Regional variations in infant and child mortality in Nigeria: a multilevel analysis. J Biosoc Sci. 2015:47(02):165-87.

30. Antai D. Migration and child immunization in Nigeria: individual- and community-level contexts. BMC Public Health. 2010;10(1):116.

31. Antai D, Moradi T. Urban Area Disadvantage and Under-5 Mortality in Nigeria: The Effect of Rapid Urbanization. Environ Health Perspect. 2010;118(6):877-83.

32. Antai D, Wedre $S$, Bellocco R, Moradi T. Migration and child health inequities in Nigeria: a multilevel analysis of contextual- and individual-level factors. Tropical Med Intl Health. 2010;15(12):1464-74.

33. Gibson M, Petticrew M, Bambra C, Sowden A, Wright KE, Whitehead M. Housing and health inequalities: a synthesis of systematic reviews of interventions aimed at different pathways linking housing and health. Health Place 2011:17:175-84

34. UN-HABITAT. State of the world's cities 2010/2011: bridging the urban divide. London: Earthscan; 2010.

35. Yakubu I, Akaateba MA, Akanbang BAA. A study of housing conditions and characteristics in the Tamale Metropolitan Area, Ghana. Habitat Intl. 2014:44:394-402

36. National Population Commission (Nigeria), ICF International. Nigeria Demographic and Health Survey. Abuja: National Population Commission (Nigeria), ICF International; 2013.

37. Rutstein S. Effect of birth intervals on mortality and health - multivariate cross country analyses with additional information for Nigeria. Washington: USAID; 2001.

38. Fayehun OA. Household environmental health hazards and child survival in Sub-Saharan Africa, DHS working papers. 2010. p. 1-34

39. WHO/UNICEF. Progress on sanitation and drinking-water - 2010 update. Geneva: WHO/UNICEF; 2010

40. ICF International. ICF international reports fourth quarter and full year 2012 results. Retrieved from https://www.icf.com/. Accessed 23 Nov 2015.

41. Brass W, Ansley JC, Paul D, Don FH, Frank L, Anatole R, Etienne WW. The Demography of Tropical Africa. Under the editorial sponsorship of the Office of Population Research, Princeton University, Princeton: Princeton University Press; 1968

42. United Nations. Manual $X$, indirect techniques for demographic estimation. 1983. 
43. Kpedekpo GMK. Essentials of Demographic Analysis for Africa. Published by Heinemann Educational Books. 1982. p. 210. ISBN: 0435973908, 9780435973902

44. Curtis MA, Corman H, Noonan K, Reichman NE. Effects of child health on housing in the urban U.S. Soc Sci Med. 2010;71:2049-56.

45. WHO. New evidence from WHO: inadequate housing causes more than 100 000 annual deaths in Europe. http://www.euro.who.int/en/media-centre/ sections/press-releases/2011/06/new-evidence-from-who-inadequate-housingcauses-more-than-100-000-annual-deaths-in-europe. Accessed 18 May 2016.

46. UN-Habitat. A world of cities: an urbanized world. London: United Nations; 2003.

47. Habib RR, Basma SH, Yertezian JS. Harboring illnesses: on the association between disease and living conditions in a Palestinian refugee camp in Lebanon. Int J Environ Health Res. 2006;16:99-111.

48. Hembree C, Galea S, Ahern J, Tracy M, Piper MT, Miller J, et al. The urban built environment and overdose mortality in New York City neighborhoods. Health Place. 2005:11:147-56.

49. Windle GS, Burholt V, Edwards RT. Housing related difficulties, housing tenure and variations in health status: evidence from older people in Wales. Health Place. 2006;12:267-78

50. Cole O, Farries JS. Re-housing on medical grounds: assessment of its effectiveness. Public Health. 1986;100:229-35.

51. Carp FM. Impact of improved living environment on health and life expectancy. Gerontologist. 1977;33:242-51.

52. Carp FM. Impact of improved housing on morale and life satisfaction Gerontologist. 1975;15:511-5.

53. Izugbara C. Whose child is dying? Household characteristics and under-5 mortality in Nigeria. South Afri J Child Health. 2014;8(1):16-22.

54. Peat JK, Dickerson J, Li J. Effects of damp and mould in the home on respiratory health: a review of the literature. Allergy. 1998;53:120-8.

55. Strachan DP. Dampness, mould growth and respiratory disease in children In: Urridge R, Ormandy D, editors. Unhealthy housing: research, remedies and reform. New York: Spon Press; 1993. p. 94-116.

56. WHO. Asthma. http://www.who.int/mediacentre/factsheets/fs307/en/. 2013 Accessed 24 May 2016

57. Eggleston PA, Arruda LK. Ecology and elimination of cockroaches and allergens in the home. J Allergy Clin Immunol. 2001;107 suppl 3:S422-9.

58. Rosenstreich $\mathrm{DL}$, Eggleston $\mathrm{P}$, Kattan $\mathrm{M}$, et al. The role of cockroach allergy and exposure to cockroach allergen in causing morbidity among inner-city children with asthma. N Engl J Med. 1997;336:1356-63.

59. Jaakkola JJ, Oie L, Nafstad P, Botten G, Samuelsen SO, Magnus P. Interior surface materials in the home and the development of bronchial obstruction in young children in Oslo, Norway. Am J Public Health. 1999;89:188-92.

60. Yang X, Chen Q, Zhang JS, An Y, Zeng J, Shaw CY. A mass transfer model for simulating VOC sorption on building materials. Atmos Environ. 2001;35: 1291-9.

61. Smith KR, Mehta S, Maeusezahl-Feuz M. Indoor air pollution from household use of solid fuels. In: World Health Organization, editor. Environmental and occupational risk factors. 2005. p. 1435-94.

62. Bruce N, Perez-Padilla R, Albalak R. Indoor air pollution in developing countries: a major environmental and public health challenge. Bull World Health Organ. 2000;78(9):1078-92.

63. Ezzati M, Kammen DM. Indoor air pollution from biomass combustion and acute respiratory infections in Kenya: an exposure-response study. Lancet. 2001:358(9282):619-24

64. Bassani DG, Jha P, Dhingra N, Kumar R. Child mortality from solid-fuel use in India: a nationally-representative case-control study. BMC Public Health. 2010;10:1-9.

65. Gajate-Garrido $G$. The impact of indoor air pollution on the incidence of life threatening respiratory illnesses: evidence from young children in Peru. J Dev Stud. 2012;49:500-15.

66. Pandey S, Lin Y. Adjusted effects of domestic violence, tobacco use, and indoor air pollution from use of solid fuel on child mortality. Matern Child Health J. 2013;17:1499-507.

67. UNICEF/WHO. Diarrhoea: why children are still dying and what can be done. Geneva: UNICEF and WHO; 2009.

68. WHO. Diarrheal disease. http://www.who.int/mediacentre/factsheets/fs330/ en. Accessed 8 Apr 2015.

69. UNICEF/WHO. (2009). Diarrhoea: why children are still dying and what can be done: UNICEF and WHO.
70. Antai D. Regional inequalities in under-5 mortality in Nigeria: A populationbased analysis of individual-and community-level determinants. Antai Popul Health Metrics. 2011;9(6). doi: 10.1186/1478-7954-9-6

71. Adebowale AS, Yusuf BO, Fagbamigbe AF. Survival probability and predictors for woman experience childhood death in Nigeria: "analysis of north-south differentials". BMC Public Health. 2012;12:430.

72. Quentin W, Olayinka A, Aka J, Akweongo P, Dinard K, Ezeh A, Hamed R, Kayembe PK, Mitike G, Bonle MT, Sundmacher L. Inequalities in child mortality in ten major African cities. BMC Med. 2014;12:95. doi:10.1186/ 1741-7015-12-95.

73. Ettarh R, Kimani J. Determinants of under- five mortality in rural and urban Kenya. Rural Remote Health. 2012;12:1812.

74. Gbenga K, Victor A, Olalekan U. Risk factors and a predictive model for underfive mortality in Nigeria: Evidence from Nigeria demographic and health survey. BMC Pregnancy Childbirth. 2012;12(10). doi: 10.1186/1471-2393-12-10.

75. Akinyemi JO, Bamgboye EA, Ayeni O. Trends in neonatal mortality in Nigeria and effects of bio-demographic and maternal characteristics. BMC Paediatr. 2015;15:36. doi:10.1186/s12887-015-0349-0.

76. Kassar SB, Melo AMC, Coutinho SB, Lima MC, Lira PIC. Determinants of neonatal death with emphasis on health care during pregnancy, childbirth and reproductive history. J Pediatr. 2013. http://dx.doi.org/10.1016/j.jped. 2012.11.005

77. Waldron I. Sex differences in infant and early childhood mortality: major causes of death and possible biological causes. In: Too young to die: genes or gender? ST/ESA/SER.A/155. New York: United Nations; 1998. p. 64-83.

78. WHO. International Workshop on Housing, Health and Climate Change: developing guidance for health protection in the built environment mitigation and adaptation responses. Geneva: WHO; 2010.

\section{Submit your next manuscript to BioMed Central and we will help you at every step:}

- We accept pre-submission inquiries

- Our selector tool helps you to find the most relevant journal

- We provide round the clock customer support

- Convenient online submission

- Thorough peer review

- Inclusion in PubMed and all major indexing services

- Maximum visibility for your research

Submit your manuscript at www.biomedcentral.com/submit 